\title{
A New Pan-Cultural Facial Expression of Emotion ${ }^{1}$
}

\author{
Paul Ekman ${ }^{2}$ and Wallace V. Friesen \\ University of California, San Francisco
}

We obtained the first evidence of a facial expression unique to contempt. Contrary to our prediction, this contempt expression was not culture-specific but was recognized by people in Estonia S.S.R., Germany, Greece, Hong Kong, Italy, Japan, Scotland, Turkey, the United States, and West Sumatra. Pan-cultural agreement about the contempt expression was as high as has been found previously for other emotions.

Evidence that people in widely divergent cultures agree in their interpretation of facial expressions of emotion, obtained 15 years ago (Ekman, Sorenson, \& Friesen, 1969; Izard, 1971), was at least partly responsible for the reawakened interest in emotion. The discovery of some universal expressions challenged the then predominant view that facial expression is determined totally by social factors (Birdwhistell, 1970), showing that it is necessary to consider biological factors as well (see Ekman, 1973, for a review of both sides of the argument).

While many now are beginning to examine emotion, there is some confusion about exactly what is being investigated. There is no agreement for example, about how many emotions there are, or about what criteria should be employed to distinguish emotions for moods, emotional traits, or emotional disorders. We (Ekman, 1984; Ekman, Friesen, \& Simons, 1985) recently proposed that emotions can be distinguished from these other affective

${ }^{1}$ We are grateful to our collaborators, Anthony Chan, Karl Heider, Rainer Krause, Rolf Kuschel, Ayhan LeCompte, Tom Pitcairn, Pio Ricci-Bitti, Klaus Scherer, Masatoshi Tomita, Athanase Tzavaras, Arnold Upmeyer, and Jaan Valsiner; to Maureen O'Sullivan for comments on this report. Paul Ekman's work is supported by a Research Scientist Award (MH 06092) from the National Institute of Mental Health.

${ }^{2}$ Address all correspondence to Paul Ekman, Human Interaction Laboratory, University of California, San Francisco, 401 Parnassus Avenue, San Francisco, California 94143. 
phenomena by virtue of their signal characteristics. For six emotions - anger, fear, surprise, sadness, disgust, and happiness - there is a unique, highly recognizable, pan-cultural facial expression. ${ }^{3}$ No unique universal facial expression has been discovered for moods (e.g., irritability is marked by anger displays but has no expression of its own), for attitudes (e.g., no expression for liking other than happy displays), or for emotional disorders (e.g., a depressed patient shows sad and fear expressions). A less radical version of our proposal would be that it is only those emotions that are the product of evolutionary forces that are distinguished by unique, pan-cultural facial expressions. There might be other emotions for which either there is no facial expression or the expression is variable across cultures. Apart from these theoretical issues, it is an important empirical matter to identify the emotions for which there are universal facial expressions.

Until our study, no one had explored whether there is an expression unique to contempt in any culture. Those who had considered contempt previously did not study it as a separate emotion, but regarded it as a minor variation on disgust, one of the pan-cultural emotions. We (Ekman \& Friesen, 1975) raised the possibility that contempt might, instead, be distinct from disgust, learned and not evolved, and culture-specific rather than universal.

Contempt differs in three ways from most of the emotions for which universal expressions have been found: (1) It has not been observed in other primates (Chevalier-Skolnikoff, 1973; Redican, 1982), while homologous expressions have been observed for anger, happiness, sadness, and a blend of fear and surprise. (2) Although developmental psychologists disagree about when each emotion is first felt or shown, there is little argument that contempt is one of the last to appear (Fridlund, Ekman, \& Oster, in press). (3) Two of the four facial expressions that have been posited as contempt signals involve unilateral facial actions, while all of the expressions known to be universal involve bilateral facial actions.

\section{METHOD}

We explored the signal value of three different expressions that have been suggested as contempt signals: (1) tightening and slightly raising the corner of the lip unilaterally, as shown in Figure 1; (2) the same expression bilaterally (Figure 2); and (3) raising the entire upper lip slightly, without tightening or raising the lip corners (Fig. 3). Photographs were taken of

\footnotetext{
${ }^{3}$ While Izard (1971) reported universal expressions also for interest and shame, Ekman (1973) has pointed out methodological problems in the findings on these two emotions, and they have not been replicated by others.
} 


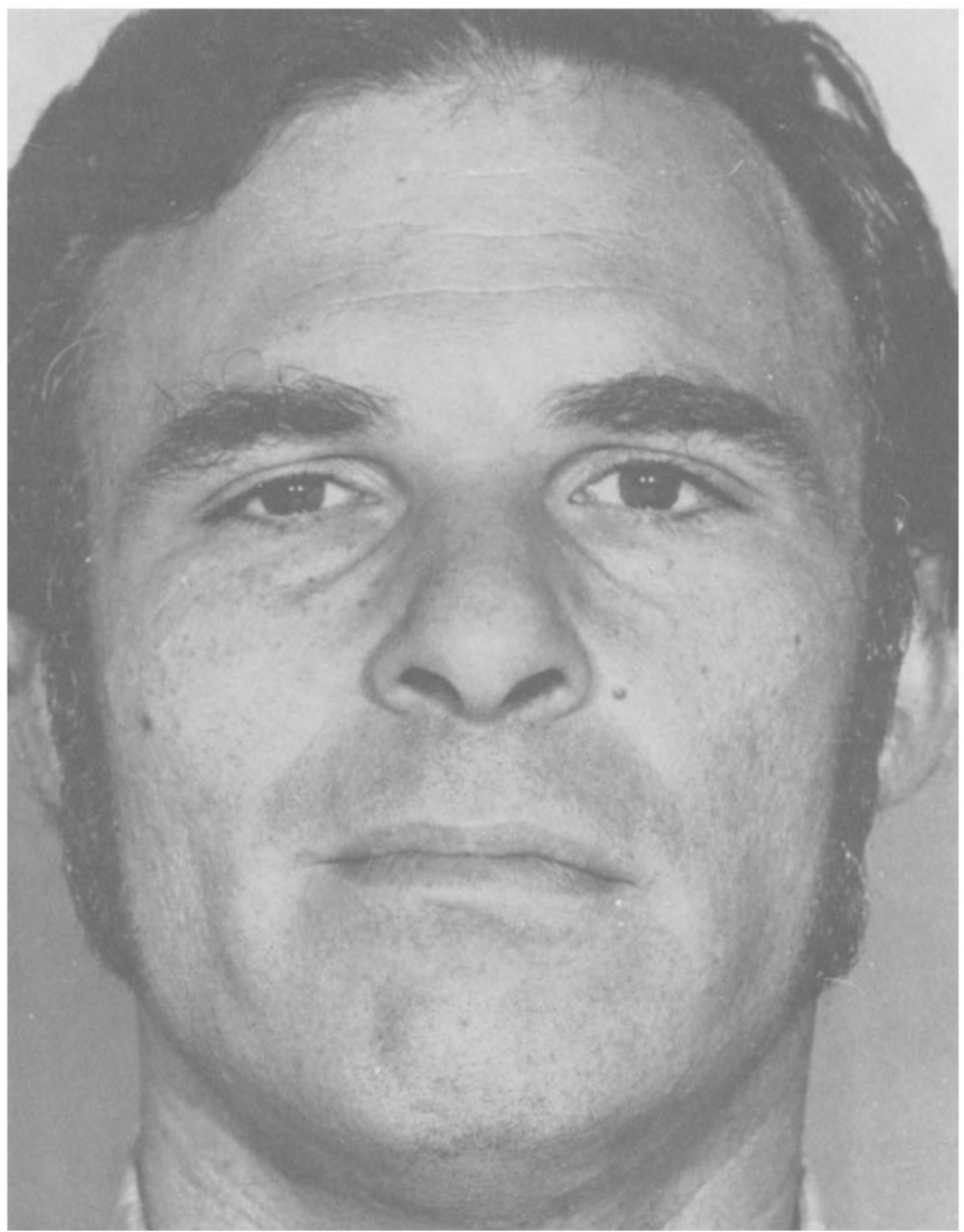

Fig. 1. The unilateral pan-culturai expression for contempt.

models as they followed instructions specifying which muscles they should contract. The pictures were scored with Ekman and Friesen's (1978) Facial Acting Coding System (FACS) to verify the muscular actions depicted in each photograph.

In addition to seeing two examples of each of these contempt expressions, subjects in each culture also saw other facial expressions, including three each for anger, disgust, fear, surprise, sadness, and happiness. These 


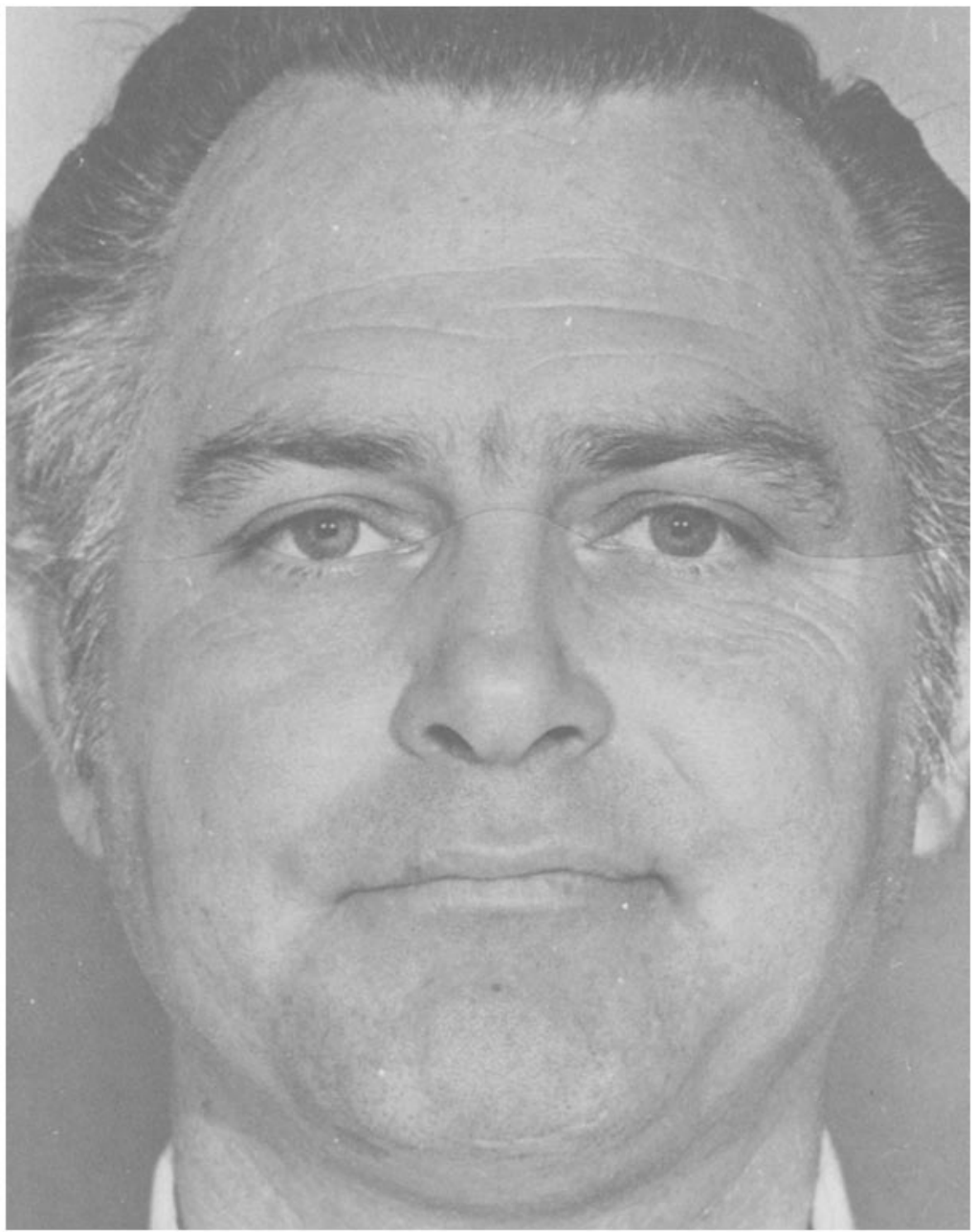

Fig. 2. The bilateral lip corner tighten and raise expression.

pictures were also produced by telling models which muscles to move and then scoring the photographs with FACS. Although the specific pictures had not been used before in cross-cultural studies, these pictures included the facial muscle actions that previous research had established as pan-cultural signals for those emotions.

Judgments about which emotion was shown in each photograph were obtained in 10 countries. With two exceptions (Turkey and Sumatra), the scientist who collected the data was a member of the culture in which the 


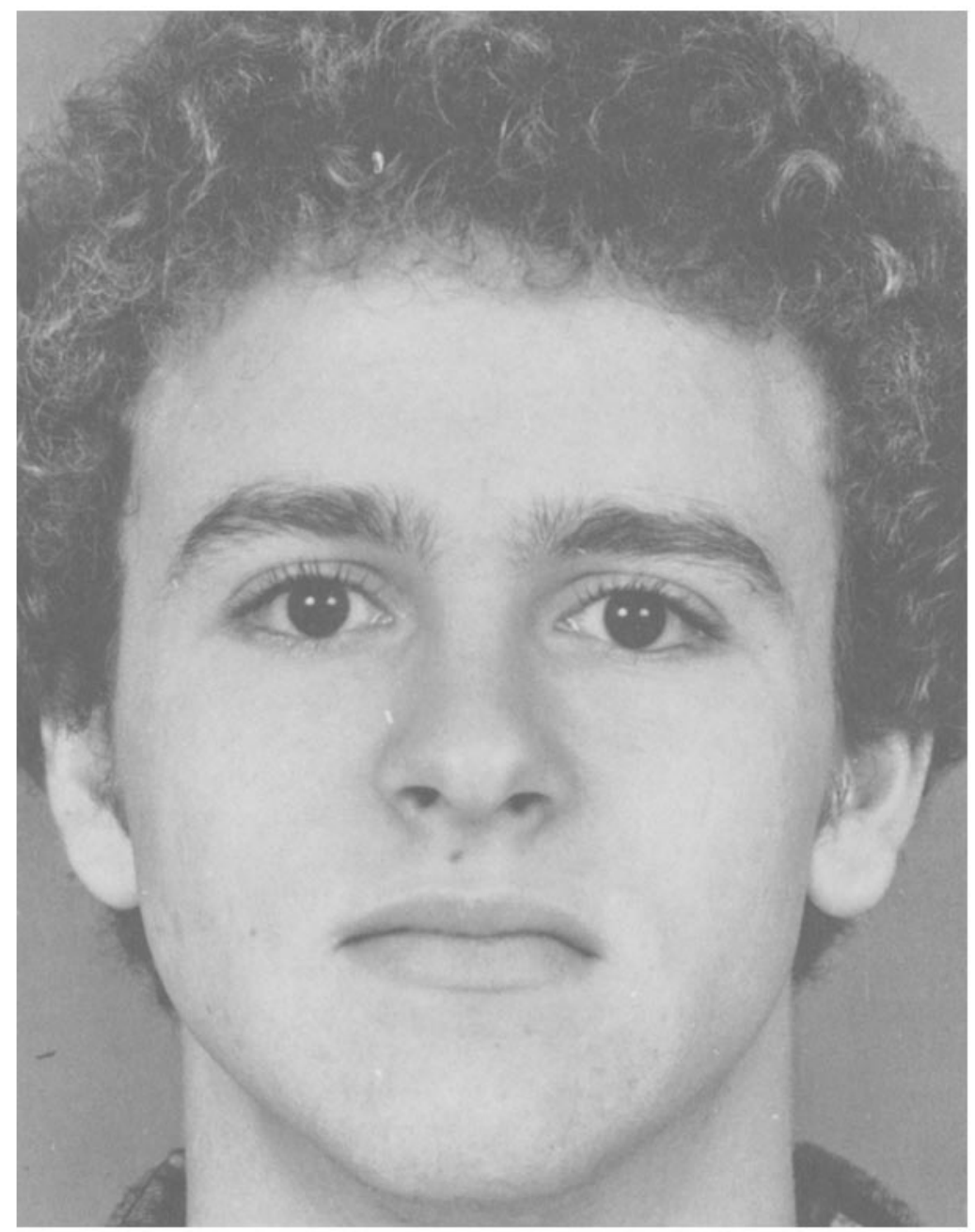

Fig. 3. The upper lip raise expression.

judgments of the faces were obtained. We sought to include a broad range of diverse cultures, but the selection finally depended upon opportunities presented by interested scientists who volunteered to collect data. The 10 countries in which the study was conducted included eight languages, and both Western and non-Western cultures. Two of these cultures - Japan and West Sumatra-are known (Ekman, 1972; Heider, 1984) to differ considerably from Western cultures in their attitudes about emotional expression. The samples and sample sizes were as follows: Estonia $=85$, Greece $=63$, Hong 
Kong $=29$, Italy $=40$, Japan $=97$, Scotland $=42$, Turkey $=65$, United States $=30$, West Germany $=67$, West Sumatra $=36$.

In each culture, the English emotion terms were translated into the native language and then translated back to verify accurate translation. Slides of the pictures were arranged into a random sequence and shown one at a time for 10 seconds to groups of subjects. Immediately after seeing each expression the subjects chose one from a list of seven emotion terms; happy, surprise, fear, sad, anger, disgust, or contempt.

\section{RESULTS}

\section{Replication of the Universality of Facial Expressions}

The results for the six emotions that had been previously investigated, excluding for the moment the contempt expressions, provided a check that the emotion words had been adequately translated and the necessary cooperation obtained within each culture. Apart from such possible procedural problems, there was another reason why cross-cultural agreement might not be found. For the first time, observers were allowed to indicate that an expression showed contempt, rather than having to make the judgment that it showed both disgust and contempt. This new choice might reduce or eliminate agreement about emotions related to contempt in appearance or experience, such as disgust, anger, or happiness.

There were 180 opportunities for agreement about what emotion was shown in each facial expression: 3(photographs of each emotion) $\times$ 6 (emotions) $\times 10$ (countries). The findings of universality were replicated: The facial expressions were judged 178 out of 180 times as showing the same emotion by the majority of the subjects, regardless of culture. Despite the addition of the contempt alternative, the level of agreement was as high as reported in previous studies. The percent of subjects across all 10 cultures who "correctly" judged the photographs (that is, who gave the judgment we expected on the basis of the muscular movement shown in the picture) was 90.1 happy, 89.5 surprise, $85.8 \mathrm{sad}, 80.4$ fear, 73.8 disgust, and 73.8 anger. These figures are within a few percentage points of the figures previously reported when contempt and disgust had been combined into a single response alternative (Ekman et al., 1969; Izard, 1971).

\section{Isolation of the One Expression that Depicts Contempt}

A $3 \times 10$ ANOVA was computed in which one factor was the three different types of contempt expression the subjects had seen: unilateral lip 
Table I. 3(Type of Contempt) $\times 10$ (Culture) ANOVA

\begin{tabular}{lrccc}
\hline & $F$ & $d f$ & $p$ & $R^{2}$ \\
\hline Culture & 4.709 & $9 / 505$ & $<.001$ & .08 \\
Contempt type & 197.074 & $2 / 504$ & $<.001$ & .44 \\
Culture $\times$ contempt & 2.334 & $18 / 1010$ & -.002 & .03 \\
\hline
\end{tabular}

corner raise and tighten, bilateral lip corner raise and tighten, and bilateral upper lip raise. The other factor was the 10 cultures. To derive an estimate of the relative magnitude of the effect sizes, an $R^{2}$ was computed for each main effect and interaction, using procedures described in Keppel (1982). The dependent variable was the number of times $(0,1$, or 2$)$ a subject judged that a type of expression showed contempt. Table I shows that although there was a significant main effect for culture, the amount of variance accounted for by culture was very small. Similarly, although the interaction between type of contempt and culture was significant, it too accounted for very little of the variance. The type of contempt judged accounted for much more of the variance than culture. The expression in which the lip corner was raised and tightened unilaterally was judged as contempt much more often ( $75 \%$ of the subjects, summing across all 10 cultures) than either the bilateral version of that expression (36\%) or the raised upper lip (19\%). For the bilateral lip corner raise and tighten, happiness was the next most frequent judgment in six of the cultures, disgust the next most common emotion in two cultures, and sad the next most frequent in two cultures. For the upper lip raise expression, disgust was the next most frequent judgment in six cultures, and sad in four cultures.

The Scheffé ${ }^{4}$ tests revealed no significant pairwise differences between cultures for the unilateral contempt expression. There also were no significant pairwise differences between cultures for the raised upper lip contempt expression. The Scheffé tests on the bilaterally raised and tightened lip corners expression revealed the following significant pairwise differences: Turkey $>$ Sumatra, Italy, Japan. These differences were not predicted, and there is no obvious a posteriori explanation. In any case, cultural differences were found for only one type of contempt expression, and this was not the one that elicited much agreement across cultures that it showed contempt.

\section{Distinguishing Contempt from Related Emotions}

The previous analyses compared three types of contempt expression and revealed that one type - the unilateral expression-elicited high agreement across cultures that it showed contempt. The question remained whether sub-

${ }^{4} \mathrm{~A}$. Tukey test, which is more powerful, was also computed and the pattern of results was the same. 
Table II. 3(Emotion Depicted) $\times 10$ (Culture) ANOVA

\begin{tabular}{lrccc}
\hline & $F$ & $d f$ & $p$ & $R^{2}$ \\
\hline Culture & 2.107 & $9 / 505$ & $<.001$ & .03 \\
Emotion depicted & 718.305 & $2 / 504$ & $<.001$ & .62 \\
Culture $\times$ emotion & 3.341 & $18 / 1010$ & $<.001$ & .04 \\
\hline
\end{tabular}

jects judge it as contempt more often than they judge contempt when they see other supposedly noncontemptuous, but related, emotional expressions. We chose to compare the unilateral contempt expression with anger and disgust expressions, because most theorists consider contempt and disgust to be highly interrelated, and, empirically, disgust and anger often have been found to be confused with each other. A $3 \times 10$ ANOVA was computed in which one factor was the three types of emotional expressions (unilateral contempt, anger, disgust) and the other factor was the 10 cultures. The dependent variable again was the number of times a subject judged a type of expression to be showing contempt. Table II shows that although the main effect for culture and the interaction between culture and type of emotion were significant, the amount of variance accounted for by each was negligible. In contrast, an extraordinarily large amount of the variance was accounted for by the type of emotion shown in the photograph. The expressions in which the lip corners were raised and tightened unilaterally were judged as contempt much more often than were either the anger or disgust expressions.

The Scheffé tests did not reveal any significant pairwise differences between cultures for contempt or for disgust. On anger, the Scheffé tests revealed that the German subjects judged the anger pictures as showing contempt more often than did the subjects from China or Greece. These differences were not predicted, and no explanation of them is readily apparent.

\section{DISCUSSION}

The results suggest that the unilateral contempt expression can be considered a pure signal that conveys a highly differentiated message recognized by most people in every culture we studied. The agreement about this contempt expression across cultures $(75 \%)$ was as high as agreement that anger pictures showed anger $(74 \%)$ or disgust pictures showed disgust $(73 \%)$. One possible limitation on our findings, however, is that all of the subjects were college students, all of whom had been exposed to some of the same mass media depictions of facial expressions. Nearly 20 years ago, concerned that our findings of universal facial expressions might be attributed to the opportunity to learn the meaning of expressions from mass media examples 
rather than being a consequence of evolution, we examined subjects in visually isolated, preliterature cultures. We found (Ekman \& Friesen, 1971) that their judgments of anger, disgust, fear, sadness, and happiness were no different from those of the college students we had studied in eight literate cultures. We also showed that once subjects could understand our task (from about the age of 5), there were no differences in how these emotions were judged as a function of either age or educational level. Given this data base on these other facial expressions of emotion, we think it quite unlikely that less educated subjects, or those not exposed to mass media, would provide different judgments of the contempt photographs. Nevertheless, data on such subjects would make our findings more conclusive. It would be difficult now to find preliterate, completely visually isolated subjects, but less educated subjects than those we studied could easily be obtained.

The discovery that there is a universal expression for contempt, but that it is only one of the three facial expressions that had been proposed, raises the possibility that prior observations about its origins may not be accurate. Not knowing exactly which expression to look for, primatologists and developmental psychologists may have missed it. New studies of nonhuman primates could help to determine whether contempt has evolved like the other emotions that have a universal expression. ${ }^{5}$ If it is not observed in any other primate, then the universal contempt expression would have to originate through species-constant learning. A universal expression that originates by this means rather than through evolution might not be connected to the biological components of emotion. For example, Ekman, Levenson, and Friesen (1983) recently found (1) different patterns of autonomic nervous system activity associated with different emotions, and (2) that voluntarily making a universal facial expression of emotion generates these involuntary, ernotion-specific physiological changes. These findings were obtained for emotions that are the product of evolution. They might not obtain if an emotional expression results from species-constant learning.

\section{REFERENCES}

Birdwhistell, R. L. (1970). Kenesics and context. Philadelphia: University of Pennsylvania Press. Chevalier-Skolnikoff, S. (1973). Facial expression of emotion in nonhuman primates. In P. Ekman (Ed.), Darwin and facial expression: A century of research in review (pp. 11-89). New York: Academic Press.

Ekman, P. (1972). Universals and cultural differences in facial expressions of emotion. In J. Cole (Ed.), Nebraska symposium on motivation, 1971 (Vol. 19, pp. 207-282). Lincoln: University of Nebraska Press.

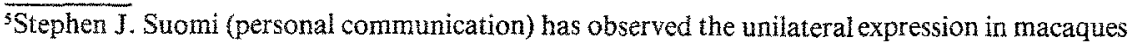
and will be pursuing systematic study.
} 
Ekman, P. (1973). Cross cultural studies of emotion. In P. Ekman (Ed.), Darwin and facial expression: A century of research in review (pp. 169-222). New York: Academic Press.

Ekman, P. (1984). Expression and the nature of emotion. In K. Scherer \& P. Ekman (Eds.), Approaches to emotion (pp. 319-343). Hillsdale, New Jersey: Erlbaum.

Ekman, P., \& Friesen, W. V. (1971). Constants across cultures in the face and emotion, Journal of Personality and Social Psychology, 17, 124-129.

Ekman, P., \& Friesen, W. V. (1975). Unmasking the face: A guide to recognizing emotions from facial clues. Englewood Cliffs, New Jersey: Prentice-Hall.

Ekman, P., \& Friesen, W. V. (1978). Facial Action Coding System: A technique for the measurement of facial movement. Palo Alto: Consulting Psychologists Press.

Ekman, P., Friesen, W. V., \& Simons, R. C. (1985). Is the startle reaction an emotion? Journal of Personality and Social Psychology, 49(5), 1416-1426.

Ekman, P., Levenson, R. W., \& Friesen, W. V. (1983). Autonomic nervous system activity distinguishes between emotions. Science, 221, 1208-1210.

Ekman, P., Sorenson, E. R., \& Friesen, W. V. (1969). Pan-cultural elements in facial displays of emotions. Science, 164(3875), 86-88.

Fridlund, A. J., Ekman, P., \& Oster, H. (in press). Facial expressions of emotion: Review of literature, 1970-1983. In A. Siegman \& L. S. Feldstein (Eds.), Nonverbal behavior and communication. Hillsdale, New Jersey: Erlbaum.

Heider, K. G. (1984). Emotion: Inner state vs. interaction. Paper presented at the meeting of the American Anthropological Association, Denver.

Izard, C. E. (1971). The face of emotion. New York: Appleton-Century-Crofts.

Keppel, (1982). Design and analysis. Englewood Cliffs, New Jersey: Prentice-Hall.

Redican, W. R. (1982). An evolutionary perspective on human facial displays. In P. Ekman (Ed.), Emotion in the human face (2nd ed. pp. 212-280). New York: Cambridge University Press. 